\title{
The Impact of Using Music and Songs on Teaching EFL in China by Non-native English Teachers
}

\author{
Margarita Vishnevskaia, Zhen Zhou* \\ School of Foreign Languages and Cultures, Ningxia University, China
}

Copyright $\subseteq 2019$ by authors, all rights reserved. Authors agree that this article remains permanently open access under the terms of the Creative Commons Attribution License 4.0 International License

\begin{abstract}
Learning English is a process that most Chinese people undergo as a requirement for their primary to tertiary education. This paper investigates the impact of incorporating music as a tool for teaching EFL in China by a non-native English teacher. There are many reasons for using music as a tool for teaching English; however, this paper also illustrates the psychological and educational benefits associated with the use of music in an EFL classroom environment. During the process of teaching English, unforeseen difficulties may occur and an experienced teacher by incorporating music might be able to deal with these difficulties to a certain degree. Emphasis is put on music being used as a means to solve and deal with practical problems that can occur. The research questions are: What are the possible reasons for using music in the classroom? What are the benefits of using music in the classroom? What problems in regards to teaching students English can be solved with the help of music? The main findings of the study are that: The use of music in the classroom can accelerate the relationship of a new teacher with students. Music can help in cases such as disruptive behavior during a lesson, help students memorize new language patterns, facilitate the assimilation of English grammar by students, give students the opportunity to relax after mastering a complex topic without departing from the topic of the lesson and help students learn the usage of new words. This paper puts forward that with the aid of music, we can make the learning English process both more interesting and exciting for students.
\end{abstract}

Keywords Studying English, Students, Music, Song, Problem, Musical Solution

\section{Introduction}

Music and songs are part of everyone's life. As a cultural phenomenon, they carry a lot of information about the culture and identity by which it was created. They affect the emotional sphere of people's lives and give a deeper insight into their minds. Songs have a large array of functions. In this article, a song is considered from the point of view of its use in the educational process. More specifically, this article discusses the use of songs as a tool for teaching Chinese students English by a foreign teacher who is not a native English speaker.

\section{Reasons for Using Music in the Classroom}

According to Kuśnierek, A. (2016), there are cognitive and affective reasons for using music in the classroom. Affective reasons are connected with Krashen's Affective Filter Hypothesis, which gives an explanation why some learners learn and others do not. According to Saricoban and Metin (2000) songs can improve the four skill areas of speaking, listening, reading, and writing. The crucial thing is that students need to develop a positive attitude towards learning (Eken 1996: 46). According to Krashen (Krashen in Kuśnierek), "for effective learning the affective filter must be weak. A weak affective filter means that a positive attitude to learning is present." Music can create a positive atmosphere in the classroom and thus can lower the affective filter. The belief that songs help improve the atmosphere in the classroom and help develop language skills has also been noted by other authors (Griffee, 1992; Domoney \& Harris, 1993; Gardner, 1993; Speh \& Ahramjian 2011).

Eken (1996 p.46) enumerates eight reasons for the use of song in a language classroom:

- to present a topic, new vocabulary or a language point

- to practice lexis

- as a material for extensive and intensive listening

- to focus on frequent learner errors in a more indirect way

- for stimulating discussions about feelings and attitudes

- provide a relaxed classroom atmosphere 
- to bring variety and fun to learning

- to encourage the use of imagination and creativity during foreign language lessons

Using songs can lead to automatic recognition and use of language patterns. According to Kuśnierek, A. (2016), the automatic process in general is fast, unstoppable, occurs without the expense of attention. Songs can help automatize the language improvement process. Essentially, the students should be placed in an environment in which it is possible to use the target language in a communicative way.

\section{Benefits of Using Music in the Classroom}

Some teachers are reluctant to use music in the classroom. They fear that it might hamper the learning environment and that the lyrics may be too complex for children to grasp. Some teachers think that the benefits associated with using music in the classroom can only be useful for a select group of musically gifted children. In fact, some of the students will benefit more than others. An outlier of students with a superior cognitive musical ability will be able to recollect and use new vocabulary easier auditory then those that haven't, but this doesn't mean that those are not in conjunction will not benefit.

\subsection{Psychological Benefits of Using Music and Songs in the Classroom}

Language and music are two systems of symbols based on sound. Sounds, such as communicative signals, convey invaluable information to a person. Language, like music, performs four functions as follows: it serves as a means of cognition, and it is the custodian of the national culture, a means of communication and expression of an idea. It is an instrument that allows us to convey an idea to another in order for them to understand. Language and music are closely interconnected and deeply penetrated into the emotional sphere of people. The use of songs in a lesson establishes a favorable psychological climate, reduces mental stress, activates the brain hemisphere linked to language, induces emotional state, and promotes interest in learning English.

\subsubsection{Motivation}

According to Kuśnierek, A. (2016), popular songs affect the lives of students and relate to their different interests and daily experiences. Almost all popular songs are related somehow to themes of friendship, love, apparitions, grief and others that are common associated feelings of people. Since most young people are interested in a wide range of cultural phenomenon outside of classes, songs can be a really motivating and unique teaching tool.

Learning songs in English is a simple task. Students easily memorize lyrics and feel the effectiveness of their training, which in turn also increases their motivation for further learning.

\subsubsection{Positive Atmosphere}

Music is one of the most effective ways of influencing the emotional behavior of school children, because they perceive singing not as an educational process, but rather as a game or an activity for relaxation. Such activities not only completely change the atmosphere of the lesson, but also contribute to unconscious recognition of new words and expressions.

Kuśnierek, A. (2016, p.24) is of the opinion that "people usually identify songs with fun, which is why learning through songs is associated with an enjoyable experience. Moreover, music may be used to relax students since for many learning a new language is a new experience".

\subsubsection{MI and listening to English Songs}

The theory of Multiple Intelligence (MI) proposed and elaborated by Gardner (1993), points out that there are a number of distinct types of intelligence possessed by each individual in varying degrees. In accordance with MI, human intelligence is categorized into at least nine primary types: verbal/linguistic intelligence, mathematical/logical intelligence, visual/spatial intelligence, body/kinesthetic intelligence, musical/rhythmic intelligence, interpersonal intelligence, intrapersonal intelligence, naturalist intelligence and existential intelligence. All of them are closely related to each other and cannot be isolated.

Teaching English at a Chinese school, teachers don't have to only use music and song lyrics, they can also include video content accompanied by cartoons that can be used as a teaching activity for students to actively partake in (to imitate activities that are sung in a song, clapping, stomping with their feet, etc.) during the singing of songs. This helps students to better comprehend and memorize material, because all possible channels of perception of information are used. The complex supply of new information, in addition to the problem of removing difficulties of perception, simultaneously develops the channels of perception that children have not sufficiently developed yet. Using visual images (video clips and actions), children draw on their well-developed visual channel of perception in order to learn a language by hearing both music and the sounds of the foreign language. Doing a warm-up, dancing or playing a certain game with music and accompanied by English phrases, kinesthetic children can more easily recall words and phrases necessary for a game or a song.

\subsection{Educational Benefits of Using Music and Songs in the Classroom}

\subsubsection{Cultural and Historical Knowledge}

Most songs are comprised of two elements word play and music. Therefore, with regards to the associated conditions of learning a foreign language, the system of 
working with the song will be very similar to the system of working on a text. It should bear in mind that the lyrics can be more-less meaningful or significant in semantic terms. There are songs, in which the text carries a large amount of information about culture and history of its origin, interesting in terms of ideas and gives a rich ground for discussion, including in terms of discussing the philosophy of life of the authors; lyric, good to the music and easy to remember; it is a self-valuable linguistic and speech work, rich in interesting vocabulary, diverse or repetitive grammatical structures, figurative expressions and stylistic techniques (Ocheretnyaya M.Z. 2016).

The song plays a special role in the sources of cultural information. At the same time, unlike educational texts of a General cultural nature, which primarily informs the student in that his intelligence and memory are affected, the song as a linguistic and cultural component has an impact on human emotions and his creative memory. As a carrier of cultural information, the song also forms the spiritual core of students.

\subsubsection{Linguistic Knowledge}

Another advantage of using songs in an English classroom is that they include linguistic information, for instance vocabulary items, pronunciation or grammar, resulting in students' acquiring new knowledge very often with no intention of direct implication. In addition, for many teachers the didactic role of music would be the first to appreciate. Songs represent forms of communication in a linguistic sense and have both melodic and rhythmic content Kuśnierek, A. (2016, p.25).

Songs are a means of lasting assimilation and expansion of vocabulary, as they include new words and expressions. In the songs, the familiar vocabulary is found in a new context, which contributes to the development of the so-called linguistic flair and increase of associative neuron connections in memory.

During songs, grammatical phenomena occur, and language is better absorbed and correlated with prior knowledge. There are training songs for the purpose of teaching and most common constructions. They are rhythmic, accompanied by explanations, comments, as well as tasks and exercises (the purpose of which is to check understanding and discuss content) (Gubina, I.P. 2017).

Songs contribute to mastering the skills of foreign pronunciation, and development of musical intonation. Learning and frequent repetition of phrases simplified in a melodic way or short songs would help correct pronunciation, articulation, as well as stress grammatical rules.

\section{Song as a Solution to Educational Problems}

As the aforementioned, music brings a lot of benefits to the teaching of a foreign language, expands the horizons of students, helps to increase vocabulary, and has a positive effect on group dynamics.

Teaching EFL in China by a non-native speaker teacher is a rather challenging task. On the one hand, when English is not your first language, teaching it brings difficulty. On the other hand, as a person who also had to learn English as a foreign language, I understand what difficulties students may encounter when studying it, and I find it an interesting task.

When I came from Russia to China and started teaching English to Chinese children, I faced a problem: what to do when your students do not speak English, and you, as a teacher, are forbidden to speak Chinese? There were many questions: Is there a universal language, intuitive to everyone? What can speed up the learning process when students barely understand you? How to establish a connection with students? How to make sure that they are not afraid of me-a foreign woman? How do I increase the effectiveness of training? How do I develop students' interest in learning?

Teaching English to Chinese children would often result in the lesson plan collapsing for various reasons. In such cases, it was necessary to improvise. Often, music came to the rescue. In the process of working with children, music became an effective and convenient educational tool. Below I illustrate how this tool works by giving examples of ways that songs solved specific problems I faced during teaching.

\subsection{Establishing a Connection between a Foreign Teacher and Students}

\subsubsection{Problem}

In many places such as China, for example, students have never seen representatives of other ethnic groups. Often young children have a fear of foreigners, especially when the appearance of a foreign teacher is very distinguishable from the appearance of the average Chinese person.

\subsubsection{Musical Solution}

Learning songs in a foreign language, students come to the understanding and realization that each group of people have their own specific features, that representatives of different cultures can see the same things from a completely different perspective. This allows students to form intercultural competence.

Thus, a song performs a socio-psychological function, strengthens the groups dynamics. In this case, when meeting new students, it is better to know which songs they have familiarity with and use that as a foundation. During the stage of students' establishing a relationship with a new foreign teacher, the use of music and songs helps to promote good relations among the teacher and students rapidly. At this stage the simpler and shorter the songs are 
the more comfortable that the students feel.

\subsection{The Lack of Variety of Memorized Templates}

\subsubsection{Problem}

Studying English, students often face the problem of lacking variation with regards to language patterns. For example in China, if you ask students "how are you?" The common answer will be: "I'm fine, thank you, and you?" If you ask their Chinese teachers, the answer will be the same.

\subsubsection{Musical Solution}

There are many songs on the topic "hello, how are you"? used for teaching simple English greetings and expressions. They are different in levels of complexity with a different degree of vocabulary. The choice of a song depends on the age and aptitude of the students. For kindergarten children, there are even songs with only one answer and Chinese subtitles.

For older children, songs with many possible answers will be suitable. Before you start learning these songs, it is important to play with the words of the songs and use actions. It's a good idea to ask students to repeat words and actions. For example, to stamp their feet and loudly shout "I'm angry!", to slap their hands on their stomach with the words "I'm hungry", smile with the words "I'm happy!" and so forth.

\subsection{Students Need a Rest}

\subsubsection{Problem}

Sometimes students need time to relax between sessions, especially if a new topic is being demonstrated, and the information load is vast. When planning a lesson, it is desirable that a rest period, in the form of a change in activity, be incorporated into the lesson without straying from the lesson topic and the logical sequence.

For example, studying the topic "The weather", after covering new vocabulary such as "windy, sunny, rainy, snowy, foggy, cold, hot, cool, cloudy", students may get confused and tired, because the new words may seem too overwhelming. Between sessions, it is important to give students a break, but not to move away from the central topic.

\subsubsection{Musical Solution}

In the interval between sessions, you can display a video clip with a song that visually shows the meaning of the words. First, you can simply show the students a video (once or twice). If the song is not difficult, you can try singing it along with the students. If there is additional class time, it is possible to hold a small competition and invite students to compete for the best performance of the song they just went over. The winners can be awarded small prizes. If we talk about students for example, in
China, it's better for them to choose very simple songs with multiple recurring words.

\subsection{Lesson Failure because of Affective Factors}

\subsubsection{Problem}

In kindergartens, lessons can be disrupted due to affective factors. For example, a new student has not yet got used to the situation of being separated from their parents and begins to cry that he wants his mom, a child wet his pants, didn't sleep enough and is whimpering or kids fought with each other. Then the attention of children is shifted and not focused on the teacher or the topic of the lesson. They then focus on the immediate environment.

\subsubsection{Musical Solution}

In such situation, to return the children's attention to the teacher, it is best to start a video with a song accompanied by great motor activity. Children react very well and quickly to music, getting up from their seats, starting singing and performing movements together with the teacher. Crying babies also quickly forget about everything and are involved in the process. The best songs are: "If you are happy, clap your hands" or "Let's go to the zoo", "Hokey-Pokey" (song, dance) is also appropriate. Children are very fond of these songs and are happy when they are singing, they like to portray emotions, dance or imitate animals.

\subsection{Material is Too Difficult for Students}

\subsubsection{Problem}

In the situation when material is too difficult for students, when the students are too young, and when you give them a task that is too difficult, it is necessary to find more creative solutions. For example, working in a Chinese kindergarten, you can face such a challenge: how to teach Chinese kindergarten children aged 1.5 to 2 years old the English alphabet?

\subsubsection{Musical Solution}

There are many popular songs for learning the English alphabet, such as "ABC song" in various variations; there are also songs with letters and sounds. However, it is very difficult for kindergarten kids to focus their attention on a song with a lot of words or on a song, where there is nothing but letters (“ABC song”). For children so young, most of the songs are either too complicated or meaningless.

For students that are too young, we can incorporate lesson design that encompasses the song, which will help students better perceive information, reduce the risk of psychological pressure and help them enjoy learning in a playful way.

In order to solve this problem, we used a Phonics Song with two Words - "A for Apple" (ChuChu TV® Studios). 
This song helps children learn the sounds of letters, as well as memorize two words for each letter. Since our students are very small and they are only $1.5-2$ years old, we also made flash cards for them corresponding to the words of the song, such as: "Apple, ant, bat, ball, cat, cup" and so on. During the lesson, children play with flash cards, memorize words in a playful way, and enjoy singing these simple songs together.

It is important that children learn no more than four new words in one lesson, and it is also important that in between lessons with foreign teachers, Chinese teachers also use this song as an ambient background for children during games. Another important point for using this song is to make sure that all the words and sounds need to be sung correctly. Sometimes it can happen that children with the letter "K" (for example) sing the sound " $\mathrm{A}$ ". This can happen because the children sing very loudly, their voices merge and muffle the music. In this case it is best to focus on individuals that have a deviation with regards to the miscorrelation of the correct sound and to correct it.

\subsection{The Need for Extra Activity}

\subsubsection{Problem}

Sometimes, lessons in the classroom are very successful and students can learn all the necessary material before the end of the lesson. In this case, it is necessary to have extra activities in order to spend the remaining time of the lesson to benefit the students, as well as to give students a sense of accomplishment for their learning to further encourage the learning process.

\subsubsection{Musical Solution}

In this case, the game "Talent Show" is very useful. By engaging in this game, students seem to be on a real talent show, performing English songs learnt from the past. Children get great pleasure from this game, and the teacher also understands what songs the children have learned well and what songs they like. There may be students who need to receive additional revision. They can surprise the teacher with new songs, and submit an idea of why songs are worth studying in the future. Thus, students, taking the initiative in choosing songs, are fully involved in the learning process as active participants. This helps develop children's love towards English lessons.

\subsection{To Help Students Memorize Many New Words and Grammatical Constructions}

\subsubsection{Problem}

For example, when students are learning a topic related to morning or daily routine, they may have difficulty memorizing a large number of words and expressions. Having large educational load, students may experience pressure or boredom.

\subsubsection{Musical Solution}

To better remember words from the topics related to morning or daily routine, a very well suited song is Get out of bed (Get out of bed. Wash your face. Clean your teeth. Bend your knees). This song can be performed very slowly at first, performing the actions corresponding to the words of the song. The speed of music gradually increases and children must sing faster and perform actions faster too. The faster the music, the harder it is to perform the actions. Children enjoy this very much. They get psychological relief and remember words and expressions quicker and with joy.

\subsection{To Learn New Structure or Patterns}

\subsubsection{Problem}

Foreign English teachers in China often face the need to study new patterns, or use simple expressions. Often assignments come in this form: "Do you like ....?" or "I can ...". Often we are confronted with the situation of the complete absence of normal teaching materials. Perhaps this is due to the difference in mentality or the differences in teaching methods. Sometimes it's just not clear what the leader expects from the teacher.

\subsubsection{Musical Solution}

If you talk about the topic "Do you like ....?", then you can find songs on this topic. For example: "Do you like broccoli?" If we talk about the topic "I can ...", then everything is much more complicated, because it's not easy to find a song that suits your students vocabulary prerequisite. Existing songs can be lexically harder for your students to comprehend or do not contain enough context. In this case, the teacher can compose a song for his / her lessons. For example, on the topic "I can ...." I wrote a song for students aged five and older. It contains repeating phrases and game activity (children move through the classroom, repeating the words of the song and making the necessary movements). The song sounds like this:

"I can fly and I can jump" - the children show how they fly, then they jump.

"I can walk and turn around" - the children show how they walk and turn around.

"I can sit and I can stand" - the children sit down and stand-up.

"I can go and hug my friend" - the children go and hug each other.

The final part of the song is very touching and the children really like it.

\section{Conclusions}

The song is a reflection of the existing picture in the world of native speakers, it reflects fears, anxieties, problems, joys, values, reflections, opinions, and therefore 
through the study of songs, another culture is more deeply comprehended. According to the experience of many teachers, songs help to solve many problems in teaching English. The songs help to eliminate the distance between the foreign teacher and students, quickly and easily learn new words and expressions, reduce stressful learning factors, reorganize lesson time, keep students attention focused on the topic currently presented, make studying complicated things easier, and increase students' motivation and passion for learning. With the help of music we can make the learning process and environment an easier, fun-filled, exciting, interesting and impactful place.

\section{REFERENCES}

[1] Eken, D. K. (1996). Ideas for using songs in the English language classroom. English Teaching Forum, 34(1), 46-47.

[2] Domoney, L. \& Harris, S. (1993). Justified and ancient: Pop music in EFL classrooms. ELT Journal, 47, 234-241

[3] Gardner, H. (1993). Frames of mind: The theory of multiple intelligences (10 anniversary ed). New York, NY: Basic Books.

[4] Griffee, D.T. (1992). Songs in action. Herfordshire, England: Phoenix ELT.

[5] Gubina, I.P. 2017. Song as an effective means of teaching a foreign language (English) at the stage of secondary vocational education. Young scientist. [Online]. 10(4), 11-15. [4 May, 2018]. Available from: https://moluch.ru/th/3/archive/72/2761

[6] Ocheretnyaya, M.Z. 2016. Педагогическое сообщество УРОКРФ. [Online]. [10 April, 2018]. Available from: https://урок.pф/library/ispolzovanie_pesni_na_urokah_ino strannogo yazika $112700 . \mathrm{html}$

[7] Krashen \& Stephen, D. (1982). Principles and practice in second language acquisition. Oxford: Pergamon Press.

[8] Kuśnierek, A. (2016). The role of music and songs in teaching English vocabulary to students. World Scientific News, 43(1), 43-48. Retrieved 1 April, 2018, from http://w ww.worldscientificnews.com/wp-content/uploads/2015/10/ WSN-431-2016-1-55.pdf

[9] Saricoban, A. \& Metin, E. (2000). Songs, Verse and Games for Teaching Grammar. The Internet TESL Journal, 6(10). Retrieved 30 March 2019, fromhttp://iteslj.org/Techniques /Saricoban-Songs.html

[10] Speh, A. J., \& Ahramjian, S. D. (2011). Teaching without a common language: synchronicities between the pedagogies of music and second language acquisition. Bulletin of the Transilvania University of Brasov, 4(53). 